\title{
Erratum
}

\section{Improved sexual behavior in male rats treated with a Chinese herbal extract: hormonal and neuronal implications}

Paola Zanoli, Augusta Benelli, Manuela Zavatti, Marianna Rivasi, Claudia Baraldi, Mario Baraldi

Asian Journal of Andrology (2009) 11: 139. doi: 10.1038/aja.2008.53; published online 22 December 2008.

Correction to: Asian Journal of Andrology (2008) 10: 937-945. doi: 10.1111/j.1745-7262.2008.00437.x

In this article, published on 1 November 2008, an error occurred in Line 6, Left column, Page 940. The word "killed" should be "anesthetized".

Asian Journal of Andrology would like to apologize to the authors and readers for the error and any confusion this may have caused. 